\title{
Efficacy of Fibrin Glue and Polyglactin Acid Sheet for Pig Liver Resection Model
}

\author{
Mitsugi Shimoda $^{\mathrm{a}, \mathrm{b}}$, Masato Kato ${ }^{\mathrm{a}}$, Yoshimi Iwasaki ${ }^{\mathrm{a}}$, Keiichi Kubota ${ }^{\mathrm{a}}$
}

\begin{abstract}
Background: Fibrin glue is commonly used to prevent bile leakage and bleeding after hepatectomy in clinical cases. Recently, several liver centers try to use polyglactin acid sheet for preventing bile leakage and bleeding in Japan. However, there is no evidence of its efficacy and safety when applied to cut liver surface after surgery. Therefore we evaluated the efficacy of fibrin glue and polyglactin acid sheet using pig liver resection model.
\end{abstract}

Methods: A chevron incision was performed under general anesthesia, followed by the left hemi-hepatectomy (approximately $40 \%$ ), using pig liver. Pigs were subsequently allocated randomly into 2 groups ( $\mathrm{n}=5$ in both); in group A, a fibrin glue (Bolheal) with polyglactin acid sheet (Neoveil) was applied to the cut surface and in group B only Bolheal was applied. After one month, we evaluated histological findings and incidence of biloma or inflammatory change at the cut surface.

Results: All of the 5 pigs in group A had fibrotic capsulated cavity at the cut surface. Inside of those cavities included necrotic liver tissues, Bolheal, and peace of Neoveil with bile juice. Histologically, Neoveil and Bolheal remained in the fibrotic tissue in normal liver tissue. In group B, only one pig had abscess at cut surface. Other four pigs showed no histological problems; Bolheal was completely integrated into the normal liver parenchyma.

Conclusions: Bolheal was very effective for liver cut surface in this experimental study. Neoveil should not be applied for cut surface.

Keywords: Fibrin glue; Polyglactin acid sheet; Liver resection; Pig; Biloma

Manuscript accepted for publication April 11, 2012

${ }^{a}$ Department of Gastroenterological Surgery, Dokkyo Medical University, Japan

${ }^{\mathrm{b}}$ Corresponding author: Mitsugi Shimoda, 880 kita-kobayashi, Mibu,

Tochigi, 321-0293, Japan. Email: mshimoda@dokkyomed.ac.jp

doi: $10.4021 / \mathrm{jcs} 54 \mathrm{w}$

\section{Introduction}

Some medical institutions commonly use fibrin glue to prevent bile leakage and bleeding post hepatectomy globally [13]. In recent years, reports from Japan revealed that polyglactin acid sheet with fibrin sealants were effective to prevent air leakage after lung resection and cerebrospinal fluid leakage after transsphenoidal surgery [4-6]. However, it is still unclear whether fibrin glue or polyglactin acid sheet have similar efficacy upon hepatectomy.

We report the results of the conducted study to assess the efficacy of fibrin glue and polyglactin acid sheet to the cut surface of the liver.

\section{Material and Methods}

\section{Experimental groups}

The study was performed using male pigs, weighing 23 $25 \mathrm{~kg}$ (SEASCO, Saitama, Japan), in accordance with the Guidelines for the Care and Use of Laboratory Animals, Dokkyo Medical University (Approval NO. 0333). After administering ketamine hydrochloride $(250 \mathrm{mg})$ and atropine $(0.5 \mathrm{mg})$ intramuscularly, the pigs were intubated and ventilated mechanically at a tidal volume of $25 \mathrm{~mL} / \mathrm{kg}$ and a rate of 12 breaths/min. During the experiment, general anesthesia was maintained with a mixture of $1-2 \%$ isoflurane and $100 \%$ oxygen. Under general anesthesia A chevron incision was performed, the left portal vein and artery were ligated, and a left hemi-hepatectomy was performed (approximately 40\%) (Fig.1). Liver transection was achieved by the crushclamping method using Pean forceps. During liver transection, each of the exposed Glisson's vessels was ligated with 2-0 or 3-0 silk. The stump of a hepatic vein was closed by continuous sutures using 4-0 proline.

Pigs were subsequently allocated randomly into 2 groups ( $\mathrm{n}=5$ in both), where either liquid fibrin glue (Bolheal: Chemo-sero Therapeutic Institute, Kumamoto, Japan) with polyglactin acid sheet (Neoveil: KYOTO Medical Planning Co., Ltd) (Group A), or Bolheal only (Group B), was applied 

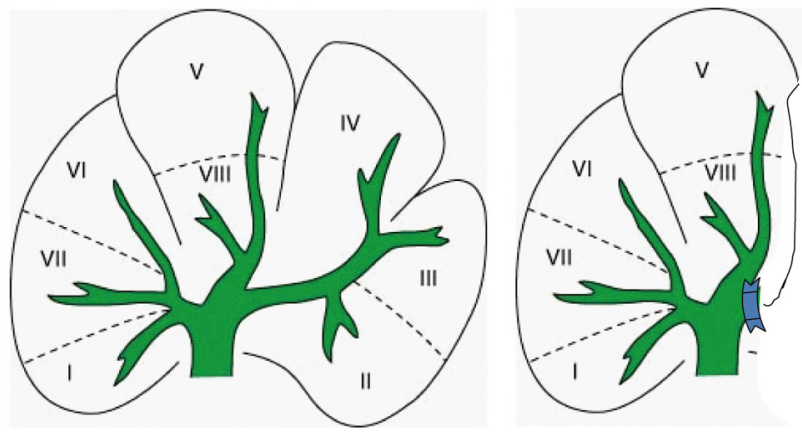

Resection

Figure 1. The left portal vein and artery was ligated, and a left hemi-hepatectomy was performed (approximately 40\%).

to the resection surface. Bolheal is composed of Solution A and B. Solution A contains $80 \mathrm{mg} / \mathrm{mL}$ of human fibrinogen, $75 \mathrm{U} / \mathrm{mL}$ of human plasma-derived coagulation factor XIII, and 1,000 KIE of bovine aprotinin. Solution B contains 250 $\mathrm{IU} / \mathrm{mL}$ of human thrombin and $5.9 \mathrm{mg} / \mathrm{mL}$ of calcium chloride. After washing the intraperitoneal space with $1000 \mathrm{~mL}$ of the saline in both groups, in group A, after $1 \mathrm{~mL}$ solution A was applied to the cut surface, and then $1 \mathrm{~cm}^{2}$ piece of Neoveil was attached to cover the surface, total amounts of solution A and B were $3 \mathrm{~mL}$ (Fig. 2 a-e). In group B, total of $3 \mathrm{~mL}$ Bolheal was applied to liver cut surface; $1 \mathrm{~mL}$ solution A was applied to the cut surface, and then followed by solution A and B to the cover the surface (Fig. 3 a-c). After opera- tion, pigs were taken care in the lobo unit, and oral in-take was free after one postoperative day. We did not administer to them any kind of antibiotics via oral or intravenously after surgery. We never disinfected the abdominal incision. After one month, we reopened the abdomen and evaluated the histological findings and incidence of biloma or inflammatory change at the cut surface of the liver.

\section{Results}

Five pigs were evaluated in each experimental group. There were no deaths within one month after surgery. a
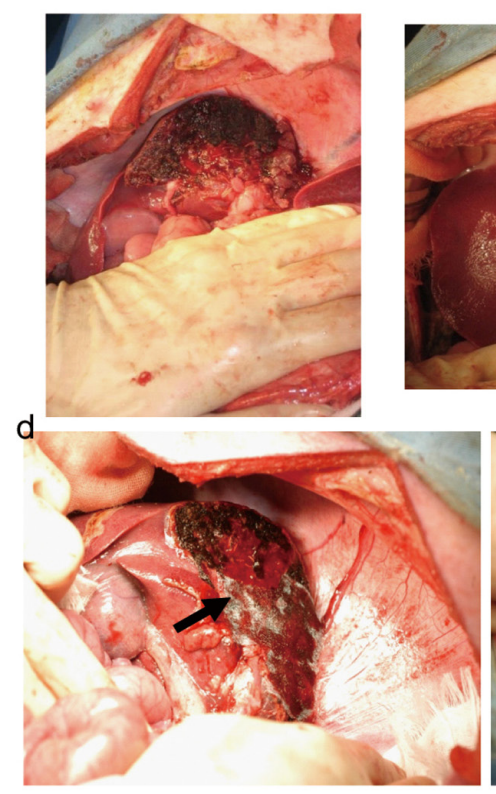

b
Bolheal with Neoveil

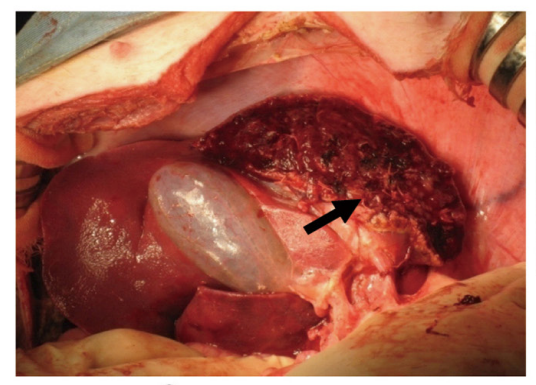

e

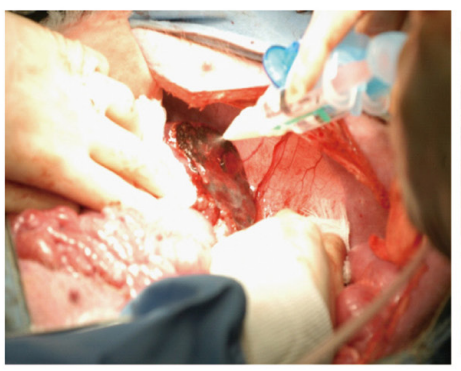

c

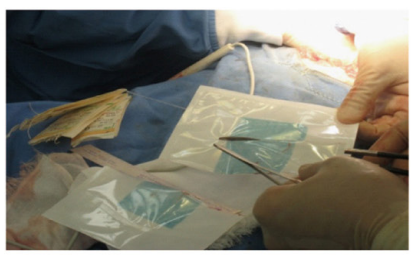

f

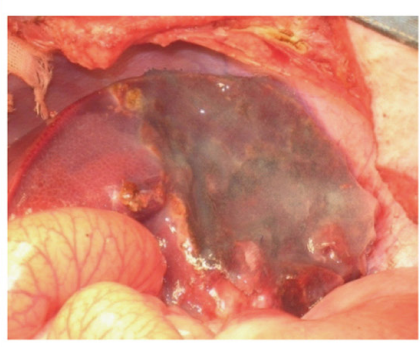

Figure 2. After controlled bleeding and bile leakage (a), solution $A$ was applying to the cut surface (b), then $1 \mathrm{~cm}^{2}$ piece of Neoveil (c) were attached covering the surface (arrow in d), and solution A and B were applied (e and f). 


\section{Bolheal only}

a

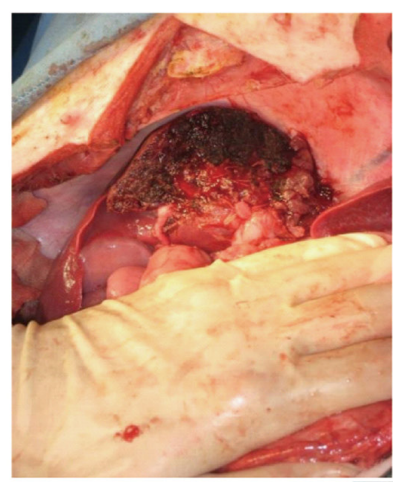

b

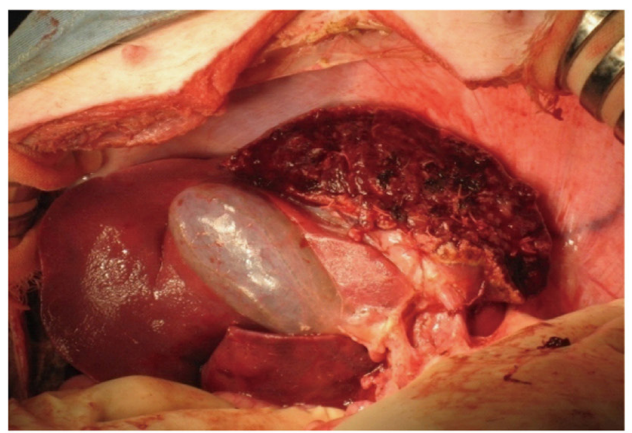

C

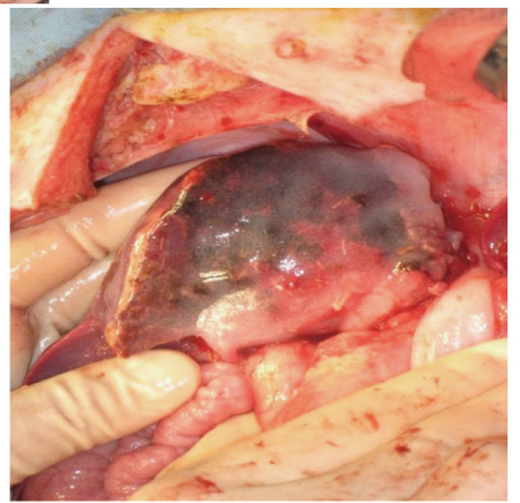

Figure 3. After liver resection, we controlled bleeding and bile leakage (a). Then, $1 \mathrm{~mL}$ solution A was applied to the cut surface (b), and then followed by solution A and B applied to the covered surface (c).
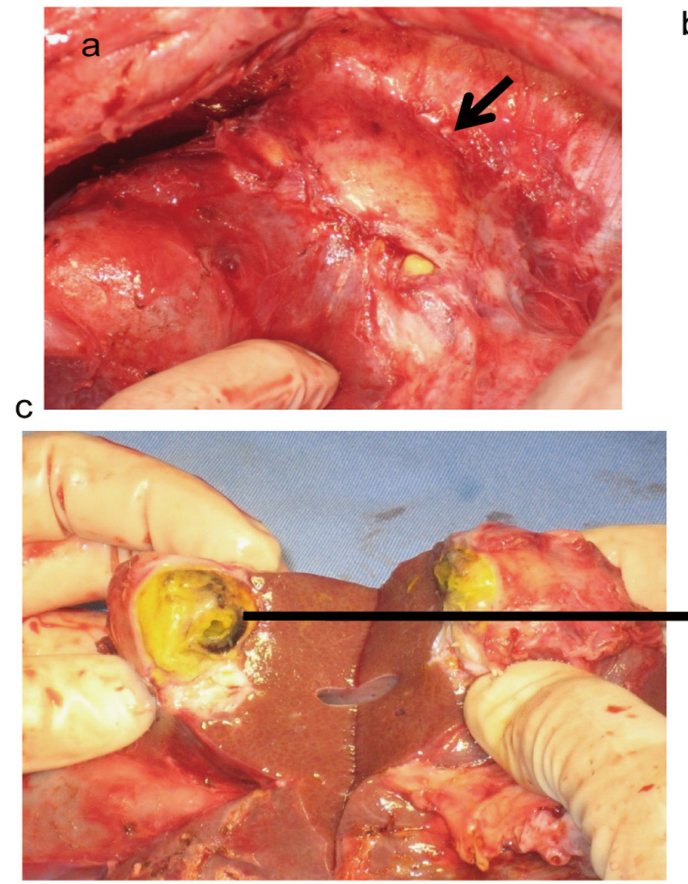

b

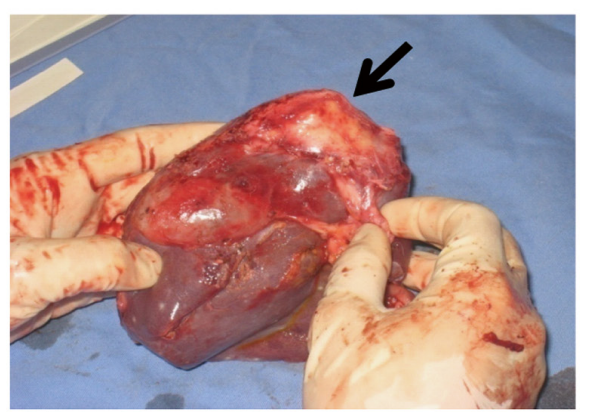

d

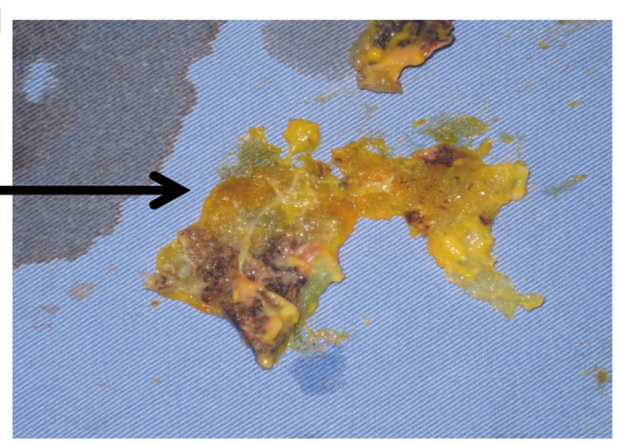

Figure 4. Fibrotic capsulated cavity revealed at the cut surface (a, b: arrows). Inside of this cavity had necrotic liver tissues, Bolheal, and peace of Neoveil with bile juice (c, d). 


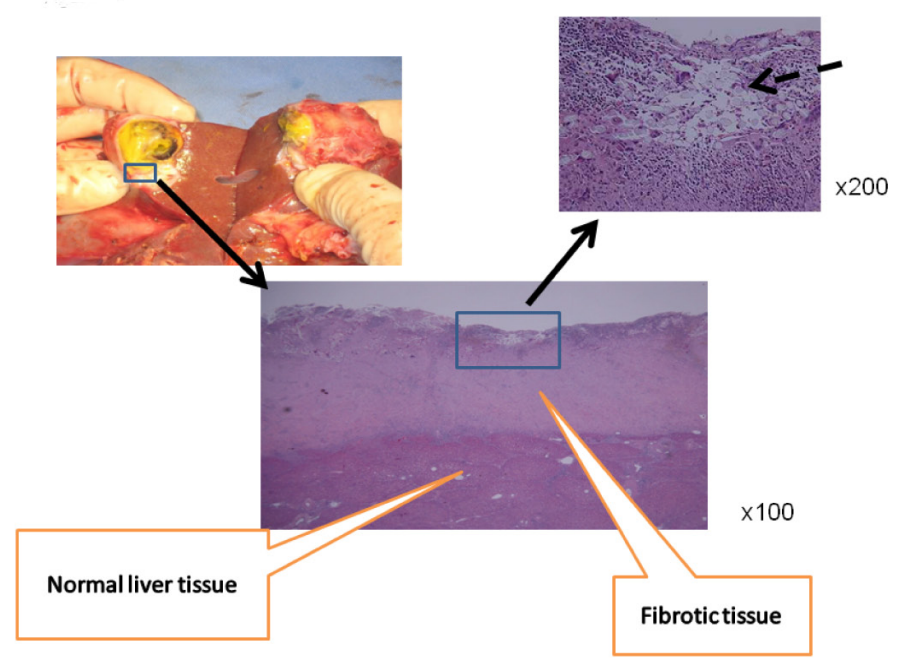

a

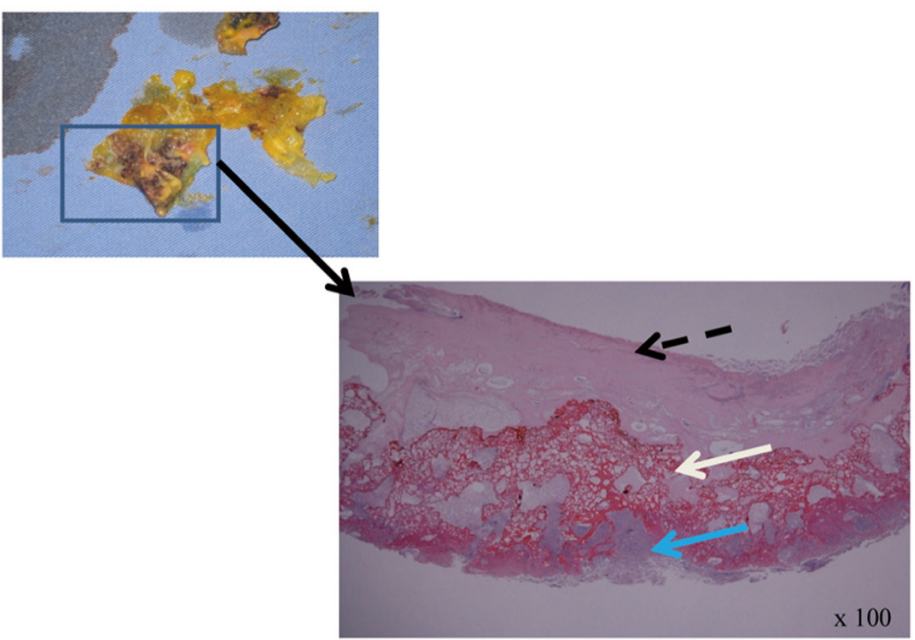

b

Figure 5. a: The fibrotic tissue and normal liver tissue were completely separate; Bolheal and Neoveil were remained on the fibrotic tissue (dot arrow); b: Neoveil, Bolheal and carbonizing liver tissue were not adapted, Bolheal; dot arrow, Neoveil; white arrow, and necrotic liver tissue (blue arrow), respectively.

In group A, all of the 5 pigs had fibrotic capsulated cavity at the cut surface. Inside of those cavities included necrotic liver tissues, Bolheal, and peace of Neoveil with bile juice. Four of the five cases had severe pus in the cavity (Fig. 4 a-d). Bacterial culture revealed E.Coli or P. aerginosa as a component of pus. Histologically, Neoveil and Bolheal remained in the fibrotic tissue in normal liver tissue (Fig. 5a, b).

In group $\mathrm{B}$, one of the 5 pigs had an abscess at the cut surface, and bacterial culture revealed existence of $\mathrm{E}$ coli. Other 4 pigs did not have any kinds of biloma and abscess
(Fig. 6a, b), and there were no histological abnormal findings. Bolheal was completely integrated to normal liver parenchyma (Fig. 7).

\section{Discussion}

Fibrin glue and sheets were commonly used to prevent bile leakage and bleeding after hepatectomy at clinical cases [13]. However, there was no evidence of its efficacy and safety to the cut surface of liver. Few experimental studies reported 


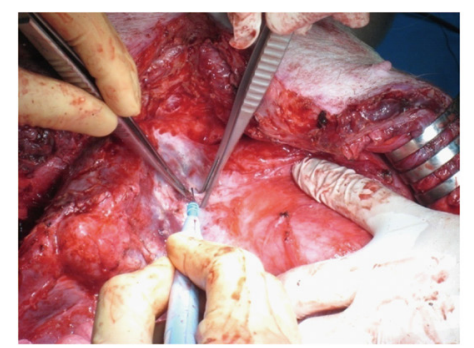

$\mathrm{a}$

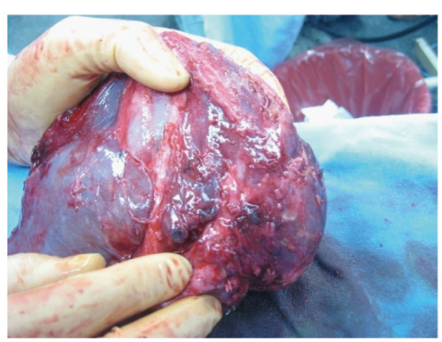

b

Figure 6. Mild adhesion revealed at the cut surface (a) and specimen did not had any kind of biloma or abscess.

good results using fibrin glue for liver cut surface. Unfortunately, these studies were conducted only using small animals for a very short interval by small incision or biopsy, hence these results were insufficient to be regarded as an evidence [7-10]. The purpose of this experimental study was to evaluate the efficacy of fibrin glue only, or fibrin glue with Neoveil, for cut liver surface after resection in one month survival model of pigs.

Bolheal is a bio-adhesive to prevent blood or bodily fluid leakage. Bolheal is composed of human fibrinogen, thrombin, human anti-hemophilic factor XIII, Calcium Chloride, and Aprotinin extracted from donated blood plasmids, heated, dried, and ant-viral processes applied. However, it is still unclear whether Neoveil is effective to prevent bile leakage and bleeding after major liver resection.

Result of this experimental study revealed that Bolheal combined with Neoveil was not effective for preventing biloma and abscess formation at liver cut surface. Both materials were not adapted to carbonizing liver tissue after using electronic scalpel, thus formulated fibrotic tissue capsules between regenerative normal liver tissue and Neoveil and Bolheal. The pus showed the presence of E coli and P. aerginosa, Bolheal with Neoveil, which was not absorbed, might function as a foreign body to accelerate bacterial infection. Rupture or penetration to other organs after one month was considered to be associated risks. On the other hand, Bolheal only was much effective in preventing bile leakage and bleeding, and only one case developed abscess, though without necrotic liver tissue. Histologically, Bolheal was integrated with normal liver tissues after one month, and was thought to have assisted in the regeneration of liver tissues. From this experimental study, Neoveil should not be used for cut surface after liver resection.

\section{Conclusion}

Single use of Bolheal is effective for in preventing bile leakage after liver resection, whereas using Neoveil with Bolheal

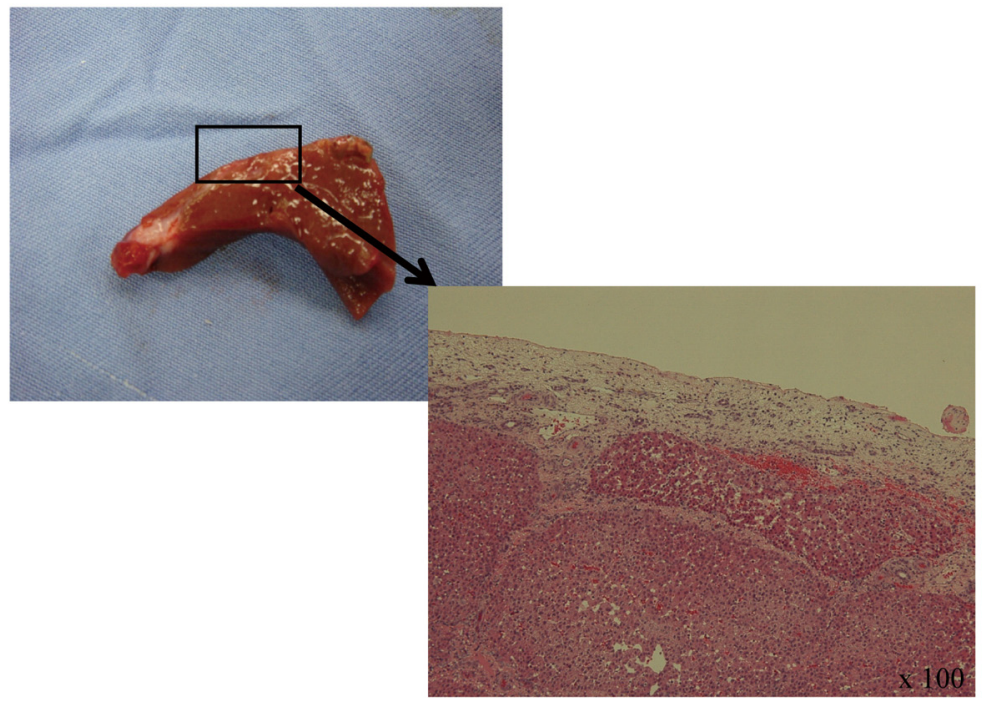

Figure 7. Histology, Bolheal was integrated with normal liver tissues, Bolheal did not find anywhere at the cut surface, fibrotic tissue was covered normal liver tissue. 
for liver cut surface remains a concern.

\section{Acknowledgement}

The authors thank Hisato Hirata and Yoshifumi Machida of the laboratory animal research center at Dokkyo University School of Medicine for their excellent technical assistance.

\section{Conflict of Interest}

None.

\section{References}

1. Noun R, Elias D, Balladur P, Bismuth H, Parc R, Lasser P, Belghiti J. Fibrin glue effectiveness and tolerance after elective liver resection: a randomized trial. Hepatogastroenterology. 1996;43(7):221-224.

2. Katkhouda N. Application of fibrin glue after hepatectomy might still be justified. Ann Surg. 2008;247(2):399400; author reply 400 .

3. Figueras J, Llado L, Miro M, Ramos E, Torras J, Fabregat J, Serrano T. Application of fibrin glue sealant after hepatectomy does not seem justified: results of a randomized study in 300 patients. Ann Surg. 2007;245(4):536542.

4. Sugawara T, Itoh Y, Hirano Y, Higashiyama N, Shimada Y, Kinouchi H, Mizoi K. Novel dural closure technique using polyglactin acid sheet prevents cerebrospinal fluid leakage after spinal surgery. Neurosurgery. 2005;57(4 Suppl):290-294; discussion 290-294.

5. Yano S, Tsuiki H, Kudo M, Kai Y, Morioka M, Takeshima H, Yumoto E, et al. Sellar repair with resorbable polyglactin acid sheet and fibrin glue in endoscopic endonasal transsphenoidal surgery. Surg Neurol. 2007;67(1):59-64; discussion 64.

6. Nakamura T, Shimizu Y, Watanabe S, Hitomi S, Kitano M, Tamada J, Matsunobe S. New bioabsorbable pledgets and non-woven fabrics made from polyglycolide (PGA) for pulmonary surgery: clinical experience. Thorac Cardiovasc Surg. 1990;38(2):81-85.

7. Chan MW, Schwaitzberg SD, Demcheva M, Vournakis J, Finkielsztein S, Connolly RJ. Comparison of poly-Nacetyl glucosamine (P-GlcNAc) with absorbable collagen (Actifoam), and fibrin sealant (Bolheal) for achieving hemostasis in a swine model of splenic hemorrhage. J Trauma. 2000;48(3):454-457; discussion 457-458.

8. Kroez M, Lang W, Dickneite G. Wound healing and degradation of the fibrin sealant Beriplast $\mathrm{P}$ following partial liver resection in rabbits. Wound Repair Regen. 2005;13(3):318-323.

9. Erdogan D, de Graaf W, van Gulik TM. Adhesive strength of fibrinogen-coated collagen patch or liquid fibrin sealant in an experimental liver resection model in pigs. Eur Surg Res. 2008;41(3):298-302.

10. Paulson EK, Stephenson GR, Neal MC, Rossin V, Lawson JH. Use of fibrin sealant as a hemostatic agent after liver biopsy in swine. J Vasc Interv Radiol. 2000;11(7):905-911. 